Int. J. Electrochem. Sci., 11 (2016) 2799 - 2824

\title{
Electrochemical Methods for Study of Influence of Selenium Nanoparticles on Antioxidant Status of Rats
}

\author{
Pavel Horky ${ }^{1}$, Branislav Ruttkay-Nedecky ${ }^{2,3}$, Lukas Nejdl ${ }^{2,4}$, Lukas Richtera ${ }^{3,4}$, Natalia Cernei ${ }^{2,3}$, \\ Miroslav Pohanka ${ }^{4}$, Pavel Kopel $^{2,3}$, Jiri Skladanka ${ }^{1}$, Pavlina Hloucalova ${ }^{1}$, Petr Slama ${ }^{5}$, \\ Pavel Nevrkla ${ }^{6}$,Veronika Mlejnkoval, Iva Klusonoval, Rene Kizek ${ }^{2,3}$ and Vojtech Adam ${ }^{2,3 *}$ \\ ${ }^{1}$ Department of Animal Nutrition and Forage Production, Faculty of Agronomy, Mendel University in \\ Brno, Zemedelska 1, CZ-613 00 Brno, Czech Republic, European Union \\ ${ }^{2}$ Central European Institute of Technology, Brno University of Technology, Technicka 3058/10, CZ- \\ 61600 Brno, Czech Republic, European Union \\ ${ }^{3}$ Department of Chemistry and Biochemistry, Mendel University in Brno, Zemedelska 1, CZ-613 00 \\ Brno, Czech Republic, European Union \\ ${ }^{4}$ Department of Geology and Pedology, Mendel University in Brno, Zemedelska 1, CZ-613 00 Brno, \\ Czech Republic, European Union \\ ${ }^{5}$ Department of Animal Morphology, Physiology and Genetics, Faculty of Agronomy, Mendel \\ University in Brno, Brno, Czech Republic, European Union \\ ${ }^{6}$ Department of Animal Breeding, Faculty of Agronomy, Mendel University in Brno, Zemedelska 1, \\ CZ-613 00 Brno, Czech Republic, European Union \\ *E-mail: vojtech.adam@mendelu.cz
}

doi: $10.20964 / 110402799$

Received: 8 January 2016 / Accepted: 27 January 2016 / Published: 1 March 2016

The aim of the experiment was to determine the effect of selenium nanoparticles (SeN) and selenium nanoparticles bound with glucose (SeN-GLU) on the antioxidant status of rats. The rats were fed with two defined forms of selenium nanoparticles for ten days. The first experimental group $(n=6)$ was dosed with SeN solution ( $0.06 \mathrm{mg}$ of Se per $\mathrm{kg}$ of body weight / day). The second experimental group $(\mathrm{n}=6)$ was dosed with SeN-GLU (0.06 $\mathrm{mg}$ of Se and $0.3 \mathrm{mg}$ of glucose per $\mathrm{kg}$ of body weight / day). In both experimental groups, the antioxidant activity was decreased in rat plasma and increased in liver, when measured using the both free radicals (FR) and Ferric Reducing Antioxidant Power (FRAP) method. Electrochemical technique (differential pulse voltammetry-DPV) was applied to analyze the content of metallothionein (MT) and heavy metals. The reduced and oxidized forms of glutathione were analyzed by high performance liquid chromatography with electrochemical detection (HPLCED). In the analysis of whole blood, a significant increase of reduced glutathione (GSH) by $41 \%$ $(\mathrm{P}<0.05)$ was observed in the SeN-GLU group compared with the control goup. Higher levels of GSH were also observed in the SeN group by $12 \%$, but without any statistical significance. On the other hand, a smaller increase in oxidized glutathione (GSSG) by $22 \%(\mathrm{P}<0.05)$ was observed for the SeNGLU group and an insignificant decrease by $13 \%$ was recorded for the SeN group which implies 
increased GSH/GSSG ratio and higher antioxidant activity for both SeN-GLU and SeN groups in the whole blood. In the assessing of GSH in erythrocytes, a linear increase was observed for each group. An increase by $14 \%$ in the SeN group and a significant increase by $19 \%$ ( $\mathrm{P}<0.05)$ in the SeN-GLU group of rats was recorded. The amount of GSSG was the highest in the SeN group (an increase by $21 \%$ ). In the liver, decrease in both forms of glutathione was observed. MT values were significantly higher in erythrocytes, plasma and liver in the groups with addition of SeN and SeN-GLU, which again implies higher antioxidant activity. The levels of zinc and copper were not significantly changed in the plasma or in the liver. From these results, it is apparent that SeN and SeN-GLU may be considered as an alternative source of selenium for improving of antioxidant status of the animal organism, which is characterized by high usability.

Keywords: selenium nanoparticles; antioxidant; rat; animal nutrition; selenium; supplementation

\section{$\underline{\text { FULL TEXT }}$}

(C) 2016 The Authors. Published by ESG (www.electrochemsci.org). This article is an open access article distributed under the terms and conditions of the Creative Commons Attribution license (http://creativecommons.org/licenses/by/4.0/). 